\begin{tabular}{|l|l|}
\hline Research Note & Open Access \\
\hline
\end{tabular}

\author{
설포닐우레아계 제초제 저항성 논잡초 발생동향 \\ 이인용 ${ }^{*} \cdot$ 원태진 $^{2} \cdot$ 서영호 $^{3} \cdot$ 김은정 ${ }^{4} \cdot$ 윤여택 $^{5} \cdot$ 조승현 ${ }^{*} \cdot$ 권오도 $^{7} \cdot$ 김상국 $^{8} \cdot$ 정완규 $^{9}$ \\ 박태선 ${ }^{10} \cdot$ 김창석 ${ }^{1} \cdot$ 이정란 $^{1} \cdot$ 문병철 $^{1} \cdot$ 박재읍 $^{1}$ \\ 1 국립농업과학원, ${ }^{2}$ 경기도 농업기술원, ${ }^{3}$ 강원도 농업기술원, ${ }^{4}$ 충청북도 농업기술원, \\ 5 충청남도 농업기술원, 전라북도 농업기술원, ${ }^{7}$ 전라남도 농업기술원, ${ }^{8}$ 경상북도 농업기술원, \\ ${ }^{9}$ 경상남도 농업기술원, ${ }^{10}$ 국립식량과학원
}

\title{
Occurrence Trends of SU-Herbicide Resistant Weeds in Paddy Fields in Korea
}

\author{
Lee In-yong ${ }^{1 *}$, Won Tae-jin ${ }^{2}$, Seo Young-ho ${ }^{3}$, Kim Eun-jung ${ }^{4}$, Yun Yeo-tack, Cho Seng-hyun ${ }^{6 *}$, \\ Kwon Oh-do ${ }^{7}$, Kim Sang-kuk ${ }^{8}$, Chung Wan-gyu ${ }^{9}$, Park Tae-seon ${ }^{10}$, Kim Chang-seok ${ }^{1}$, \\ Lee Jeongran ${ }^{1}$, Moon Byung-chul ${ }^{1}$ and Park Jae-eup ${ }^{1}$ \\ ${ }^{1}$ National Academy of Agricultural Science, RDA, Suwon 441-707, Korea \\ ${ }^{2}$ Gyeonggido Agricultural Research \& Extension Services, Hwaseong 445-784, Korea \\ ${ }^{3}$ Gangwondo Agricultural Research \& Extension Services, Chuncheon 200-150, Korea \\ ${ }^{4}$ Chungchengbukdo Agricultural Research \& Extension Services, Chengwon 363-883, Korea \\ ${ }^{5}$ Chungchengnamdo Agricultural Research \& Extension Services, Yesan 340-861, Korea \\ ${ }^{6}$ Jeollabukdo Agricultural Research \& Extension Services, Iksan 570-704, Korea \\ ${ }^{7}$ Jeollanamdo Agricultural Research \& Extension Services, Naju 520-715, Korea \\ ${ }^{8}$ Gyeongsangbukdo Agricultural Research \& Extension Services, Daegu 702-708, Korea \\ ${ }^{9}$ Gyeongsangnamdo Agricultural Research \& Extension Services, Jinju 660-985, Korea \\ ${ }^{10}$ National Institute of Crop Science, RDA, Suwon 441-857, Korea \\ (Received on September 10, 2013; Revised on September 12, 2013; Accepted on September 13, 2013)
}

\begin{abstract}
National Academy of Agricultural Science and eight province Agricultural Research \& Extension Services investigated the occurring area of herbicide resistant weeds in paddy field of Korea. In order to estimate the occurring areas of herbicide resistant weeds, we collected paddy soils randomly from 3,200 sites in 2011 and 2012 , and treated $30 \mathrm{~kg} \mathrm{ha}^{-1}$ of pyrazosulfuron-ethyl+pyriminobac-methyl GR to the paddy soil. 176,870 ha, approximately $22.1 \%$ of cultivated area excluding organic and eco-friendly cultivated area, was estimated to be infested by SUherbicide resistant paddy field weeds. Several species of resistant weeds were occurred at Jeonranam-do with $44.3 \%$, followed by $30.5 \%$ at Chungchungnam-do, $27.8 \%$ at Chungchungbuk-do, and $24.5 \%$ at Jeonrabuk-do, respectively. Monochoria vaginalis showed the highest distribution with 57,018 ha, $32.2 \%$ followed by Scirpus juncoides, and Lindernia procumbens, respectively.
\end{abstract}

Key words: Herbicide resistant weed, Paddy field weeds, Sulfonylurea herbicides

제초제 저항성이란 농업적으로 추천된 제초제 처리농도 에서 효과적으로 방제되던 잡초 가운데 연용으로 인하여 방제되지 않고 생존하거나 번식하는 생태형으로 유전능력 을 갖는 것을 말한다(Kim and Shin, 2007). 이런 제초제

*Corresponding author:

Phone) +82-31-290-0418, Fax) +82-31-291-0503

E-mail) leeinyong@korea.kr
저항성잡초를 국내에서 처음으로 보고한 것은 Park et al. (1999)이다.

Park et al., (1999)은 충남 서산 간척지논에서 10여년동 안 농가에서 사용하였던 pyrazodulfuron-ethyl+molinate $5.07 \%$ 입제에 대한 논잡초 방제효과가 낮다는 농가의 민 원을 과학적으로 입증하는 과정에서 물옥잠이 설포닐우레 아(SU)계 제초제에 대해 저항성이 있다는 것을 확인하였 
다. 그 후 많은 잡초연구자들에 의해서 물달개비, 미국외 풀, 마디꽃, 올챙이고랭이, 알방동사니, 올미, 새섬매자기, 쇠털골 등 10 종이 $\mathrm{SU}$ 계 제초제 대해 저항성을 보고하였 다(Im et al., 2003; Im 2010; Im et al., 2004; Kuk et al., 2004; Kwon et al., 2002; Kwon et al., 2009; Park et al., 2009, 2001). 그러나 Park et al.(2011)은 우리나라는 일본 과 제초제 사용 패턴이 유사하여 $\mathrm{SU}$ 계 제초제 저항성잡 초는 더 늘어날 것이라고 하였다.

한편 충남 서산 간척지와 전북 김제지역에는 화본과잡초 (피) 방제용 제초제인 cyhalofop-butyl 등 ACCase 저해 제초 제에 저항성을 보이는 논피(강피)와 물피 생태형이 보고되 어(Im, 2009; Im et al., 2009; Lim et al., 2010; Park et al., 2010), 제초제 저항성잡초의 발생양상이 다변화되고 있음을 확인하였다. 그리고 $\mathrm{ALS}$ 억제제와 ACCase 저해제간에 교 차저항성을 보이는 피가 발생되고 있다고 보고되었다(Lee et al., 2011; Lim et al., 2010; Park et al., 2010 ).

현재(2013년 9월 10일) 제초제 저항성잡초는 전 세계적 으로 61개국 66작물에서 218초종(쌍자엽 129초종, 단자엽 89초종)이 발생되고 있으며, 저항성을 유발하는 제초제는 148종이다(www.weedscience.com). 이들 제초제 저항성 잡 초는 1980년대에는 주로 triazine계 제초제가 주를 이루었 고, 1990년대 및 2000년대에는 SU계 제초제에 대한 보고 가 급격히 증가하였다.

제초제 저항성잡초를 효율적으로 관리하기 위해서는 이 들 잡초의 발생정도를 파악하는 것이 무엇보다 시급하고 중요하다. 이런 제초제 저항성잡초 발생 모니터링을 통하 여 농가에서 사용하는 제초제의 사용패턴 파악으로 향후 에 어떤 잡초가 저항성으로 유발될 수 있다는 것도 추론 할 수 있고, 제초제 저항성잡초의 확산을 억제하기 위한 방안도 제시될 수 있다.

이에 농촌진흥청 국립농업과학원에서는 2011년과 2012
년 2년동안 8 개도 농업기술원과 공동으로 제초제 저항성 잡초 발생 모니터링을 실시하여 그 발생면적을 추정한 결 과를 보고하는 바이다.

\section{SU계 제초제 저항성잡초 검정을 위한 논토양 채취}

SU계 제초제 저항성잡초 발생조사는 2011년과 2012년, 2 년동안 8 개도 농업기술원에서 각각 실시하였다. 각 도별 로 벼 재배양식, 지대, 토양특성 등을 고려하여 8개 지역 을 임의로 나누고 각 도별로 400지점, 전국 3,200지점에 서 논흙을 채취하였다. 조사지점은 각 도별 모든 시군이 포함되도록 하였다. 논흙은 각 지점당 $0 \sim 20 \mathrm{~cm}$ 사이의 흙 을 2 3 kg씩 3 4군데에서 채취한 후 혼합하여 각도 농업 기술원의 온실에서 시험하였다.

\section{SU계 제초제 저항성잡초 검정방법}

채취한 논흙은 와그너 포트( $1 / 5,000 \mathrm{a})$ 또는 4각 포트 $(40 \times 50 \times 10 \mathrm{~cm})$ 에 넣고 물로 진탕한 다음, 10 일 후에 $\mathrm{SU}$ 계 혼합 제초제인 피라조설퓨론에틸- 피리미노박메틸입제 를 $30 \mathrm{~kg} \mathrm{ha}^{-1}$ 처리하였다. 약제처리 후 20 일에 생존한 잡 초를 $\mathrm{SU}$ 계 제초제 저항성잡초로 간주하고 각 도별 $\mathrm{SU}$ 계 제초제 저항성잡초 발생면적을 추정하였다.

\section{SU계 제초제 저항성 논잡초 발생현황}

도별 SU계 제초제 저항성잡초 발생면적을 보면, Table 1 과 같이 전국 벼 재배면적(유기 및 친환경농업 벼 재배 면적 제외)의 $22.1 \%$ 인 $176,870 \mathrm{ha}$ 로 확인되었다. 2008 년에 는 106,951 ha (Park et al., 2011), 2011년에는 167,081 ha (Lee et al., 2012)와 비교하면 각각 60,130 ha와 9,789 ha가 늘어났다. 이런 결과는 Lee et al., (2012)이 보고한 바와 같이 SU계 제초제 저항성을 보인 광엽잡초와 ACCase 저 해제와 ALS에 대해 교차 저항성을 보인 피의 발생면적이

Table 1. Occurrence rate of sulfonylurea herbicide resistant weeds in 2011 and 2012 by provinces.

\begin{tabular}{lccc}
\hline \hline \multicolumn{1}{c}{ Province } & $\begin{array}{c}\text { Area of } \\
\text { Cultivated rice (ha) }\end{array}$ & $\begin{array}{c}\text { Ratio of occurred herbicide } \\
\text { resistant weeds (\%) }\end{array}$ & $\begin{array}{c}\text { Area of herbicide } \\
\text { resistant weeds (ha) }\end{array}$ \\
\hline Gyeonggi-do & 91,727 & 12.0 & 11,039 \\
Gangwon-do & 34,772 & 24.5 & 8,519 \\
Chungchengbuk-do & 46,758 & 28.7 & 13,438 \\
Chungchengnam-do & 151,026 & 29.2 & 44,099 \\
Jeollabuk-do & 132,678 & 18.4 & 24,413 \\
Jeollanam-do & 117,848 & 44.3 & 52,206 \\
Gyeongsangbuk-do & 141,005 & 15.8 & 22,280 \\
Gyeongsangnam-do & 84,017 & 1.0 & 876 \\
Total & 799,831 & 22.1 & 176,870 \\
\hline
\end{tabular}

${ }^{\mathrm{x}}$ Of rice cultivation acreage $(854,000 \mathrm{ha})$, acreage of organic and environment-friendly farming $(54,169$ ha) was excluded. 
늘어났기 때문으로 판단된다. 이미 Lee et al. (2011)과 Lim et al. (2010)은 충남과 전남북에서 ACCase 저해제와 ALS 억제제에 저항성을 보이는 강피의 발생을 확인하였고 방 제방법을 보고한 바 있다.

발생비율을 보면, 전라남도가 논 면적의 $44.3 \%$ 로 제일 많이 발생되었고, 그 다음으로는 충청남도로 $29.2 \%$, 충청 북도 $28.7 \%$, 강원도 $24.5 \%$, 전라북도 $18.4 \%$ 순이었다. 이 들 제초제 저항성 논잡초의 발생현황이 전라남도와 충청 남도, 전라북도 등과 같이 상대적으로 높은 이유는 Lee et al. (2012)이 보고한 바와 같이 간척지와 담수직파논에 많 아 벼에 상대적으로 안전한 $\mathrm{SU}$ 계를 선호하고 연용하였기

Table 2. Occurrence area of sulfonylurea herbicides resistant weeds in rice paddy fields.

\begin{tabular}{|c|c|c|c|c|}
\hline \multirow{2}{*}{$\begin{array}{l}\text { Weed species } \\
\text { Weed }\end{array}$} & \multicolumn{4}{|c|}{ Occurrence area (ha) } \\
\hline & 2004 & 2006 & 2008 & 2012 \\
\hline Monochoria vaginalis & 34,327 & 42,012 & 62,560 & $\begin{array}{l}57,018 \\
(32.2 \%)\end{array}$ \\
\hline Scirpus juncoides & 494 & 906 & 12,060 & $\begin{array}{l}33,803 \\
(19.1 \%)\end{array}$ \\
\hline Echinochloa oryzicola & - & - & 17 & $\begin{array}{l}13,581 \\
(7.7 \%)\end{array}$ \\
\hline Cyperus difformis & 12,800 & 13,171 & 14,230 & $\begin{array}{l}13,085 \\
(7.4 \%)\end{array}$ \\
\hline Lindernia dubia & 32 & 33 & 33 & $\begin{array}{l}11,301 \\
(6.4 \%)\end{array}$ \\
\hline Ludwigia prostrata & - & - & - & $\begin{array}{l}10,719 \\
(6.0 \%)\end{array}$ \\
\hline $\begin{array}{l}\text { Rotala indica var. } \\
\text { uliginosa }\end{array}$ & 5 & 5 & 5 & $\begin{array}{c}2,047 \\
(1.2 \%)\end{array}$ \\
\hline Sagittaria pygmaea & - & 17 & 17 & $\begin{array}{c}701 \\
(0.4 \%)\end{array}$ \\
\hline $\begin{array}{l}\text { Eleocharis acicularis } \\
\text { for. longiseta }\end{array}$ & - & 5 & 27 & $\begin{array}{c}589 \\
(0.3 \%)\end{array}$ \\
\hline Sagittaria triflolia & - & - & - & $\begin{array}{c}191 \\
(0.1 \%)\end{array}$ \\
\hline Scirpus maritimus & 4,000 & 6,000 & 8,000 & $\begin{array}{c}111 \\
(0.1 \%)\end{array}$ \\
\hline Monochoria korsakowi & 10,000 & 10,000 & 10,000 & - \\
\hline Biyxa aubertii & - & 2 & 2 & - \\
\hline $\begin{array}{l}\text { Lindernia procumbens } \\
\text { (assumed) }\end{array}$ & - & - & - & $\begin{array}{l}33,135 \\
(10.7 \%)\end{array}$ \\
\hline $\begin{array}{l}\text { Diplachne fusca } \\
\text { (assumed) }\end{array}$ & - & - & - & $\begin{array}{c}353 \\
(0.2 \%)\end{array}$ \\
\hline $\begin{array}{l}\text { Dopatrium junceum } \\
\text { (assumed) }\end{array}$ & - & - & - & $\begin{array}{c}236 \\
(0.2 \%)\end{array}$ \\
\hline Total & 61,658 & 72,241 & 106,951 & 176,870 \\
\hline
\end{tabular}

때문으로 판단된다.

\section{SU계 제초제 저항성 초종별 발생현황}

$\mathrm{SU}$ 계 제초제 저항성 논잡초의 초종별 발생면적은 Table 2 와 같다. 발생면적이 가장 넓은 초종은 물달개비로서 $57,018 \mathrm{ha}$ 로 전체 저항성 논잡초의 $32.2 \%$ 를 차지하였으며, 그 다음으로 올챙이고랭이(33,803 ha, $19.1 \%)$, 논피(강피), 알 방동사니, 미국외풀 순이었다. Park et al. (2011)은 우리나 라와 일본의 농업상황을 비교하면서 향후에는 물달개비와 올챙이고랭이의 발생면적이 늘어나 우점할 것이라는 보고 와 유사하다.

여뀌바늘은 학계에 정식으로 $\mathrm{SU}$ 계 제초제 저항성잡초 로 보고된 바는 없지만, Park (2012)에 의해 저항성잡초로 확인되었다. 그리고 밭뚝외풀도 $\mathrm{SU}$ 계 저항성잡초로 보고 되지는 않았지만, 미국외풀과 같은 현삼과 일년생잡초이 고 어릴 때에는 식별이 쉽지 않아 미국외풀을 밭뚝외풀로 오류하였을 가능성도 배제할 수 없다. Lee et al., (2009) 에 의하면 밭뚝외풀속에는 밭뚝외풀, 미국외풀, 논뚝외풀 등 6종이 있으며, 육안으로 쉽게 분류할 수 없다고 하였다.

2008년 조사결과와 비교하면, 발생면적이 줄어든 잡초 는 물달개비, 새섬매자기인 반면에 늘어난 잡초는 올챙이 고랭이, 미국외풀, 마디꽃, 벗풀, 쇠털골, 논피(강피)이다. 온실 검증으로 발생 확인이 안 된 제초제 저항성잡초로 물옥잠은 주로 충남 서산 간척지논에서 발생되고 있으며, 올챙이자리는 전남 나주와 해남 간척지 논에서 문제되고 있다. 새롭게 제초제 저항성잡초로 의심되는 갯드렁새, 밭 뚝외풀, 등애풀은 감수성 계통과 비교하여 농도시험 등을 통해 제초제 저항성 잡초 여부의 확인이 필요하다.

\section{요 약}

제초제 저항성 논잡초 발생면적은 국립농업과학원과 전 국 8개도 농업기술원 공동으로 2011년과 2012년에 조사 하였다. 8 개도 3,200 지점에서 논훍을 채취하여 피라조설퓨 론에틸 - 피리미노박메틸입제를 $30 \mathrm{~kg} \mathrm{ha}^{-1}$ 처리하여 설포 닐우레아(SU)계 제초제 저항성 논잡초의 발생면적을 추산 하였다. 전국 벼 재배면적(유기 및 친환경농업 벼 재배면 적 제외)의 $22.1 \%$ 인 $176,870 \mathrm{ha}$ 에서 $\mathrm{SU}$ 계 제초제 저항성 논잡초가 발생되었다. 발생비율을 보면, 전라남도가 논 면 적의 $44.3 \%$ 로 제일 많이 발생되었고, 그 다음으로는 충청 남도로 $30.5 \%$, 충청북도 $27.8 \%$, 강원도 $24.5 \%$ 순이었다. 제초제 저항성 논잡초 중 발생면적이 가장 넓은 초종은 물달개비로서 전체 $32.2 \%(57,018 \mathrm{ha})$ 를 차지하였으며, 그 다음으로 올챙이고랭이, 밭뚝외풀 순이었다. 
주요어: 논잡초, 설포닐우레아계 제초제, 제초제 저항성잡초

\section{Acknowledgment}

This study was supported by a AGENDA (No.PJ0077 98) grant of Rural Development Administration, Republic of Korea.

\section{References}

Im, I.B. 2009. Control and emergence of herbicides resistant Echinochloa oryzicola in paddy field of Korea. Korean J. Weed Sci. 29(Supp. 2):103-104. (In Korean)

Im, I.B. 2010. Control and emergence of sulfonylurea herbicides resistant Lemna paucicostata in paddy field of Korea. Korean J. Weed Sci. 30(Supp. 1): 60-61. (In Korean)

Im, I.B., Kang, J.G., Kim, S. and Kuk, Y.I. 2004. Control of sulfonylurea resistant Lindernia dubia (L.) Pennell in the rice paddy field. Korean J. Weed Sci. 24(1):7-13. (In Korean)

Im, I.B., Kim, S., Kang, J.G. and Na, S.Y. 2003. Weed control of small flatsedge (Cyperus difformis L.) with resistant response to sulfonylurea herbicides in th paddy of Korea. Korean J. Weed Sci. 23(1):63-70. (In Korean)

Im S.U., Park, M.W., Yook M.J. and Kim, D.S. 2009. Resistance to ACCase inhibitor cyhalofop-butyl in Echinochloa crus-galli var. crus-galli collected in Seosan, Korea. Korean J. Weed Sci. 29(2):178-184. (In Korean)

International Survey of Herbicide Resistant Weeds. http:// www.weedscience.com (Accessed Sep. 10, 2013)

Kim, K.U., Shin, D.H. 2007. The principle of weed science. pp. 352-358. Kyungpook National University Press. Daegu, Korea.

Kuk, Y.I., Kwon, O.D. and Im, I.B. 2004. Effective herbicides by application timing for control of sulfonylurea resistant Monochoria vaginals, Lindernia dubia, and Rotala indica in wet-seeding and machine transplanting rice culture. Korean J. Weed Sci. 24(1):30-42. (In Korean)

Kwon, O.D., Kuk, Y.I., Lee, D.J., Shin, H.R., Park, I.J., et al. 2002. Growth and yield of rice as affected by competitive period of resistant Monochoria vaginalis biotypes to sulfonylurea herbicides. Korean J. Weed Sci. 22(2):147-153. (In Korean)
Kwon, O.D., Kuk, Y.I., Cho, S.H. and Shin, H.R. 2009. Alternative herbicides for Eleocharis acicularis resistant to sulfonylurea in Jeonnam, Korea. Korean J. Weed Sci. 29(3):251-260. (In Korean)

Lee, I.Y., Kwon, O.D., Kim, C.S., Lee, J. Shin, H.R., et al. 2011. Weeding effect of Echinochloa oryzoides resistant to ACCase and ALS inhibitors by leaf stages. Korean J. Weed Sci. 31(2):183-191. (In Korean)

Lee, I.Y., Park, J.S., Seo, Y.H., Kim, E.J., Lee, S.G., et al. 2012. Occurrence trends of herbicide resistant weeds in paddy fields in Korea. Korean J. Weed Sci. 32(2):121-126. (In Korean)

Lee, W.J., Oh, Y.J., Kim, C.S. and Kang, C.K. 2009. Anatomical and palynological characteristics of Lindernia. Korean J. Weed Sci. 29(Supp. 2):111. (In Korean)

Lim, S.H., Song, J.S., Zhang C. and Kim, D.S. 2010. ACCase inhibitor cyhalofop-butyl resistance in Echinochloa oryzicola collected in Chungnam and Jeonbuk province, Korea. Korean J. Weed Sci. 30(Supp. 1):45-46. (In Korean)

Park, T.S. 2012. Report of 'Study of the monitoring and management in herbicidal resistant weeds'. RDA Report (not printed). (In Korean)

Park, T.S., Kang, C.K., Park, J.E., Ku, B.I., Park, H.K., et al. 2009. Identification and management of sulfonylurea-resistant biotype of Scirpus planiculmis in reclaimed paddy fields, Korea. Korean J. Weed Sci. 29(Supp. 1):35-37. (In Korean) Park, T.S., Kim, C.S., Moon, B.C., Lee, I.Y. Lim, S.T., et al. 2001. Occurrence and control of Lindernia dubia (L.) Pennell var. dubia, sulfonylurea resistant biotype in paddy fields in southern areas of Korea. Korean J. Weed Sci. 21(1):33-41. (In Korean) Park, T.S., Kim, C.S., Park, J.E., Oh Y.K., Kim, K.U., et al. 1999. Sulfonylurea-resistant biotype of Monochroria korsakowii in reclaimed paddy fields in Seosan, Korea. Korean J. Weed Sci. 19(4):340-344. (In Korean)

Park, T.S., Ku, B.I., Kang, S.K., Choi, M.K., Park, H.K., et al. 2010. Response of the resistant biotype of Echinochloa oryzoides to ACCase and ALS inhibitor, and effect of alternative herbicides. Korean J. Weed Sci. 30(3):291-299. (In Korean)

Park, T.S., Lee, I.Y., Seong, K.Y., Cho, H.S., Park, H.K., et al. 2011. Status and prospect of herbicide resistant weeds in rice field of Korea. Korean J. Weed Sci. 31(2):119-133. (In Korean) 